\title{
Cryptophanes for Methane and Xenon Encapsulation: A Comparative DFT Study of Binding Properties and NMR Chemical Shifts
}

\author{
Taye B. Demissie, ${ }^{*, a, b}$ Kenneth Ruud, ${ }^{a}$ and Jørn H. Hansen ${ }^{*, b}$ \\ ${ }^{a}$ Hylleraas Centre for Quantum Molecular Sciences, Department of Chemistry, UiT The \\ Arctic University of Norway, 9037 Troms $\phi$, Norway. \\ ${ }^{b}$ Organic Chemistry Group, Department of Chemistry, UiT The Arctic University of Norway, \\ 9037 Troms $\phi$, Norway.
}

\begin{abstract}
The host-guest

chemistry

of

cryptophanes is an active research area because of its applications in sensor design, targeting small molecules and atoms in environmental and

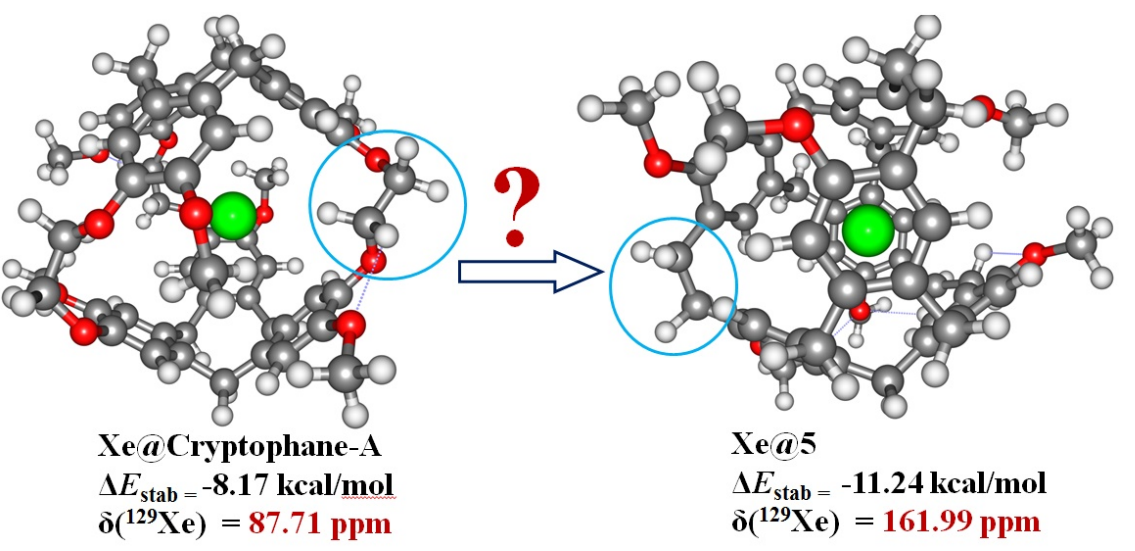
medical sciences. As such, the computational prediction of binding energies and nuclear magnetic resonance (NMR) properties of different cryptophane complexes are of interest to both theoreticians and experimentalists working in host-guest based sensor development. Herein we present a study of 10 known and some newly proposed cryptophanes using density functional theory (DFT) calculations. We benchmark the description of non-bonding interactions by different DFT functionals against spin-component-scaled, second-order Møller-Plesset theory (SCS-MP2) and predict novel host molecules with enhanced affinity towards methane and Xenon - two representative systems of high interest. We demonstrate the power and limitations of the different computational methods in describing the binding and NMR-properties of these established and novel host systems. The results show the importance of including dispersion corrections in the DFT functionals. The overall analysis of the 
dispersion corrections indicated that results obtained from pure DFT functionals should be used cautiously when drawing conclusions for molecular systems with considerable weak interactions. Proposed analogues of cryptophane-A, where the alkoxy bridges are replaced by alkyl chains, are predicted to display enhanced affinity towards both methane and Xenon.

\section{Introduction}

The host-guest chemistry of cryptophanes is an active research area because of increasing interest in the complexation of small molecules and atoms for sensor design in environmental and medical sciences. Cryptophanes are roughly spherical cage molecules consisting of two relatively rigid aromatic bowl-shaped cyclotriveratrylene sub-units connected by three flexible aliphatic linkers. Among them is cryptophane-A which is composed of two equivalent cyclotriguaiacylene (CTG) caps connected by three ethylenedioxy linkers where one methoxy group is attached to each of the benzene rings. ${ }^{1}$ Cryptophane-A can exist in two diastereomeric forms, of which the anti-diastereomer has been isolated. ${ }^{2}$ They form host-guest complexes with a range of small molecules, of which methane, chloroform and water ${ }^{3-5}$ as well as xenon are the most common guests. ${ }^{2,6-8}$ The complexes are generally characterized by weak non-covalent host-guest interactions. Among the potential applications of cryptophane complexes are drug formulation and delivery, ${ }^{9}$ molecular recognition and storage, ${ }^{10-12}$ magnetic resonance imaging (MRI) contrast agents, ${ }^{13}$ and sensors. ${ }^{14-16}$

${ }^{129} \mathrm{Xe}\left(\right.$ spin-1/2) is an attractive MRI contrast agent. ${ }^{13}$ It is non-toxic, polarizable, inert and has millimolar solubility ( $\sim 5 \mathrm{mM})$ in water. ${ }^{17}$ The Xe@cryptophane-A system has been shown to be useful as a biosensor ${ }^{15,16}$ in cancer detection. Xe@cryptophane biosensors can also be targeted to protein receptors by appropriate functionalization and identified in vivo by changes to the magnetic resonance frequency of the bound ${ }^{129} \mathrm{Xe}$ nucleus. ${ }^{18} \mathrm{Cryptophane- \textrm {A } \text { has }}$ also recently been used in optical gas sensors that can be used to detect dissolved methane in air and sea water based on refractive index modulations..$^{19,20}$

The chemical synthesis of cryptophanes is demanding. The process requires activated benzyl alcohol derivatives to react in multistep reactions to give rise to the strained cyclotribenzylene (CTB) compounds. However, considerable interest in the numerous applications of these molecules has led to continued efforts in functionalization and systematic structural variation of cryptophanes..$^{5,7,18-21}$ For instance, derivatives of cryptophane-A were first synthesized and described in the early 1980 s by Canceill et al.22 Diversification of the 
structures allows for modification and optimization of host-guest characteristics and other

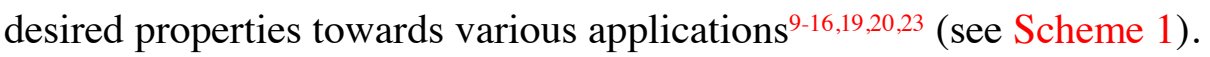
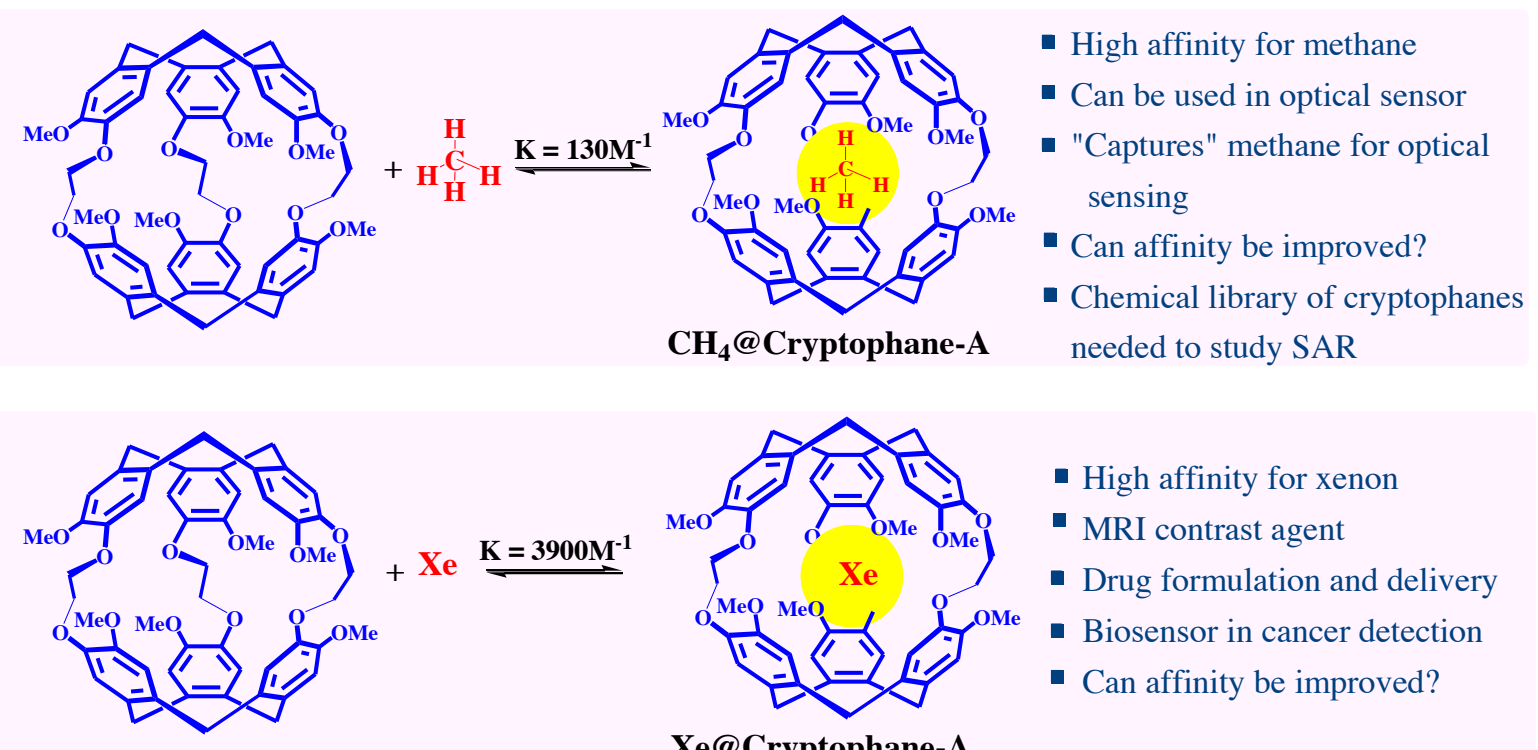

Xe@Cryptophane-A

Scheme 1. Cryptophane-A complexation and applications in sensing (methane and MRI). The $\mathrm{K}$ values are association constants at $300 \mathrm{~K}$ for $\mathrm{CH}_{4} @$ Cryptophane- $\mathrm{A}^{21}$ and at $278 \mathrm{~K}$ for Xe@Cryptophane-A. ${ }^{14}$ SAR stands for structure activity relationship.

It is well known that xenon can be hyperpolarized and it has been used in biosensing ${ }^{24,25}$ and magnetic resonance imaging (MRI). ${ }^{26,27}$ Since it is inert, delivering xenon to a specific biological target is a challenge. However, by using suitable cryptophane-bioactive conjugates, one can effectively bind xenon in a variety of biochemical environments. As such, the ability to compute accurate binding energies and NMR properties of different cryptophane complexes is of importance to both theoreticians and experimentalists working in the areas of methaneand ${ }^{129} \mathrm{Xe}$-based sensors.

In this work, we have studied 10 different cryptophanes using high-level DFT calculations. Some of these are known, and some we propose herein for the first time. We have constructed these by changing the cryptophane-A scaffold, either by replacing the methoxy groups by methyl, or by modifying the linkers to hydrocarbons or different linker lengths (see Scheme 2). The major objectives of this study are: (1) to compare the ability of the different DFT functionals to describe the non-bonding interactions in these host-guest complexes compared to the spin-component-scaled, second-order Møller-Plesset theory (SCS-MP2), proposed by Grimme ${ }^{28}$ which exploits the ability to separately scale the singlet and triplet 
electron pair contributions to the correlation energy; (2) to predict novel host molecules with enhanced affinity towards methane and xenon; and (3) to study the relation between the structures of the hosts and magnetic resonance frequency (NMR chemical shift) of the bound guest molecules.

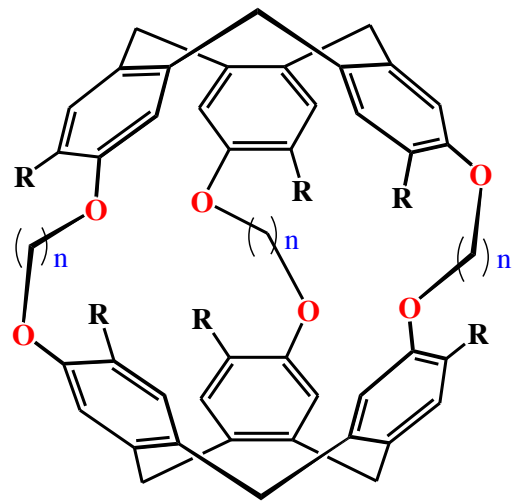

with alkyldioxy linkers

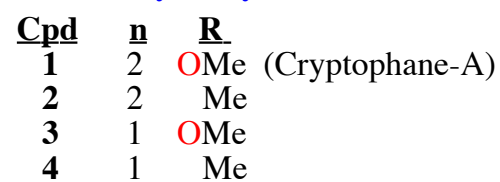

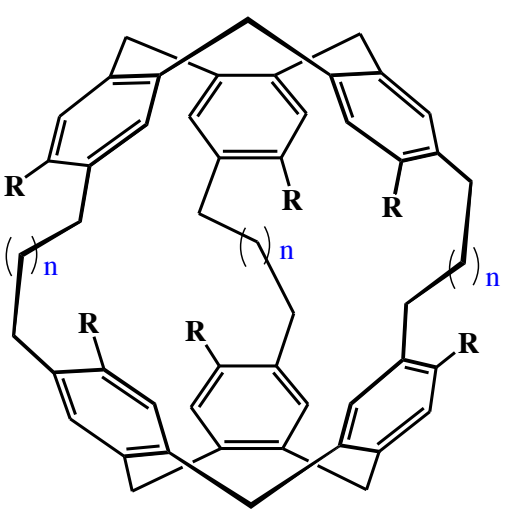

with alkyl linkers

$\begin{array}{llr}\text { Cpd } & \underline{\mathbf{n}} & \underline{\mathbf{R}} \\ \mathbf{5} & 0 & \mathrm{OMe} \\ \mathbf{6} & 0 & \mathrm{Me} \\ \mathbf{7} & 1 & \mathrm{OMe} \\ \mathbf{8} & 1 & \mathrm{Me} \\ \mathbf{9} & 2 & \mathrm{OMe} \\ \mathbf{1 0} & 2 & \mathrm{Me}\end{array}$

Scheme 2. The two basic cavitand skeletons studied herein where the CTG linkers are either alkyldioxy or an alkyl chains and the side attachments are either methoxy or methyl groups.

\section{Computational Details}

The geometry optimization of cryptophane-A 1 was started from the X-ray structure of cryptophane- $\mathrm{D}^{29}$ by replacing the hydrogens with methoxy substituents on the second ring. The structure of $\mathbf{2}$ was built by starting from the optimized geometry of $\mathbf{1}$ (by replacing the methoxy groups with methyl). The initial structure of $\mathbf{3}$ was generated starting from the X-ray structure of cryptophane- $111^{30}$ and replacing the hydrogens with methoxy substituents, and replacing the methoxy groups with methyl for $\mathbf{4}$. Since we were unable to find similar molecular systems for molecules 5 - 10, we built them starting from the optimized geometry of $\mathbf{1}$. After optimizing the structure of the host, the guests were inserted and the complexes were optimized using the same computational approach. Conformers of the cages and the corresponding complexes were generated using either the MarvinView ${ }^{31}$ or PCModel $^{32}$ program packages employing the MMFF94 force field with a strict optimization limit. For the molecules with $-\mathrm{O}-\mathrm{CH}_{2}-\mathrm{CH}_{2}-\mathrm{O}-$ or $-\mathrm{CH}_{2}-\mathrm{CH}_{2}-\mathrm{CH}_{2}-\mathrm{CH}_{2}$ - bridges, a total of 20 conformers (a combination of the different bridge dihedral angles as well as orientation of the methoxy groups in the latter bridge types) for each 
molecule were selected based on their relative stabilities. These molecular mechanics (MM) minimized conformers were used for further subsequent geometry optimizations using ๑B97X-D ${ }^{33} / 6-311 G(d, p)^{34}$ to identify the most stable conformers. This approach followed by DFT calculations has been shown to give stable conformers in good agreement with the experimental structural parameters for similar kinds of compounds..$^{35}$

The conformational freedom of the methoxy and methyl substituents was thoroughly analysed by running calculations using $\omega B 97 X-D / 6-31 G(d)$. After this analysis, the most stable structures were used for further geometry optimizations and frequency calculations using the 6-311G $(\mathrm{d}, \mathrm{p})^{34}$ basis set for the light atoms and Def2-TZVP ${ }^{36}$ together with effective core potentials (ECPs) for Xe to account for relativistic effects. It has previously been demonstrated that the 6-311G(d,p) basis set is appropriate for DFT studies of such complexes. ${ }^{37,38} \mathrm{We}$ used the functionals $₫ B 97 X-D,{ }^{33}$ B3LYP ${ }^{39-41}$ B3LYP-D3, ${ }^{39-42}$ B3LYP-D3BJ ${ }^{39-42}$ and M06-L ${ }^{43}$ in this study. Previous studies of host-guest complexes have indicated that SCS-MP2 better predicts the change in energies of complexes with weak non-covalent interactions ${ }^{38,44,45}$ compared to other commonly used DFT functionals. ${ }^{38,44,45}$ Hence, in addition to the DFT functionals, we also used SCS-MP2 together with the cc-pVDZ basis set as a benchmark. The change in free energies were all calculated at standard conditions (298.15 K and $1 \mathrm{~atm})$. All DFT geometry optimizations were performed using the Gaussian 09 program package ${ }^{46}$ where the optimized geometries were confirmed to be real minima on the potential energy surface with no imaginary frequencies by performing a normal-mode vibrational analysis at the same level of theory. To take into account bulk solvent effects, all the calculations were performed within a continuum solvent model by employing the polarizable continuum model (PCM) in its integral equation formalism variant (IEF-PCM). ${ }^{47-49}$ Since we primarily focussed on the application of the studied complexes in aqueous environments, we used water as a solvent in all the geometry optimizations, frequency calculations and energy analyses. The SCS-MP2 geometry optimizations were performed starting from the $\omega B 97 X-D$ optimized geometry using the Turbomole ${ }^{50}$ program package.

To be consistent with the supramolecular approach, ${ }^{51,52}$ we define the interaction energy of the host and the guest molecules as:

$$
\Delta E_{\mathrm{int}}(\mathrm{A} @ \mathrm{~B})=E(\mathrm{~A} @ \mathrm{~B})-E(\mathrm{~A})-E(\mathrm{~B})
$$

where the geometries of $\mathrm{A}$ and $\mathrm{B}$ were the same as they are in the complex. For all supermolecular calculations, the Boys-Bernardi counterpoise scheme ${ }^{53}$ was applied in order to 
reduce the basis-set superposition errors (BSSE). In this approach both molecules A and B were calculated in the $\mathrm{A} @ \mathrm{~B}$ orbital basis set. The binding energy, an energy parameter that describes the stability of the complexes, is calculated as the difference between the energies at the optimized geometries of the $\mathrm{A} @ \mathrm{~B}$ complex and the sum of the energies of the isolated $\mathrm{A}$ and B molecules:

$\Delta E_{\text {bind }}=\Delta E_{\text {int }}(\mathrm{A} @ \mathrm{~B})+\Delta E_{\text {defom }}(\mathrm{A})+\Delta E_{\text {deform }}(\mathrm{B})$

where $\Delta E_{\text {int }}(\mathrm{A} @ \mathrm{~B})$ is the interaction energy for the $\mathrm{A} @ \mathrm{~B}$ complex $(\mathrm{Eq} .1)$, and $\Delta E_{\text {deform }}(\mathrm{A})$ and $\Delta E_{\text {deform }}(\mathrm{B})$ are the deformation energies for molecules $\mathrm{A}$ and $\mathrm{B}$, respectively. The latter energies were calculated as the difference between the energy of molecule $\mathrm{A}$ in the complex A@B orbital basis set and A in its isolated state (the same also applies to B).

In order to approximately take into account the total (electronic and nuclear) stabilization of the complexes, the difference between the zero-point vibrational energies (ZPVE) of the complex and the sum of the contributions for the constituent molecules ( $\triangle \mathrm{ZPVE}$ ) was added to the binding energy obtained from Eq. (2). This formulation (Eq. (3)) is adopted to see the overall effect of the encapsulation stabilization energies because we study both larger cages where the guest can enter without any modification and smaller cages where the guest may need some driving force to enter.

$$
\Delta E_{\mathrm{stab}}=\Delta E_{\mathrm{bind}}+\Delta \mathrm{ZPVE}
$$

Xenon is a heavy atom where relativistic effects play a major role in its NMR properties. Hence, we used B3LYP-D3 together with the spin-orbit-zeroth-order-regular approximation $(\mathrm{SO}-\mathrm{ZORA})^{54,55}$ and the slater type relativistically optimized all-electron triple-zeta double polarized $(\mathrm{TZ2P})^{56}$ basis set as implemented in $\mathrm{ADF}^{57}$ program package to calculate the absolute shielding constants. This approach has been shown to provide results in good agreement with experimental results for related xenon complexed cryptophanes. ${ }^{58} \mathrm{We}$ used the Gauge-Including Atomic Obitals (GIAO) ${ }^{59}$ to ensure fast basis-set convergence and originindependent results. The reported carbon and proton chemical shifts are referenced to tetramethylsilane (TMS). Since we primarily focussed on the analysis of the NMR properties in aqueous environment, we used water as solvent for both the methane and xenon complexes. As an additional study, we also report xenon chemical shifts calculated in gas phase and referenced to the free ${ }^{129} \mathrm{Xe}$ atom absolute shielding constant calculated in gas-phase. This approach has been shown to provide accurate chemical shifts in related studies. ${ }^{18,38,60}$ In order 
to further improve the accuracy of the xenon chemical shifts, we scaled the results according to literature data ${ }^{18,61}$ using the equation:

$$
\delta_{\text {scale }(129 \mathrm{Xe})}=\left(\delta_{\text {calc }}+30.97\right) / 1.198
$$

where $\delta_{\text {scale }}$ and $\delta_{\text {calc }}$ are the scaled and calculated chemical shifts, respectively. This scaling approach has been shown to provide a good correlation between the calculated and experimental ${ }^{129} \mathrm{Xe}$ chemical shifts for related cryptophane complexes. ${ }^{18}$

\section{Results and Discussion}

\subsection{Conformational Analysis}

The conformational analysis for the ethylene oxide and butylene bridge linkers are presented in Table S1 of the Electronic Supporting Information (ESI). Due to the flexibility of the bridges connecting the CTG units, there are different possible conformations for all molecules. For the cryptophane derivatives as well as their complexes listed in Table S1 of the ESI, there are at least 20 possible conformers $\left(G_{+} G_{+} G_{+}, G_{-} G_{-} G_{-}, G_{+} G_{+} G_{-}, G_{-} G_{-} G_{+}, T_{+} T_{+} T_{+}\right.$, $T_{-} T_{-} T_{-}, T_{+} T_{+} T_{-}, T_{-} T_{-} T_{+}, G_{-} G_{+} T_{+}, G_{-} G_{-} T_{+}, G_{-} G_{-} T_{-}, G_{-} T_{+} T_{+}, G_{-} T_{-} T_{-}, G_{-} T_{-} T_{+}, G_{+} G_{+} T_{-}, G_{+} T_{+} T_{+}$, $\mathrm{G}_{+} \mathrm{T}_{-} \mathrm{T}_{-}, \mathrm{G}_{+} \mathrm{T}_{-} \mathrm{T}_{+}, \mathrm{G}_{+} \mathrm{G}_{+} \mathrm{T}_{+}$, and $\mathrm{G}_{-} \mathrm{G}_{+} \mathrm{T}_{-}$; where $\mathrm{G}$ refers to gauche type conformation and $\mathrm{T}$ refers to trans type conformation (with \pm signs) for the $-\mathrm{O}-\mathrm{CH}_{2}-\mathrm{CH}_{2}-\mathrm{O}-$ and $-\mathrm{CH}_{2}-\mathrm{CH}_{2}-\mathrm{CH}_{2}-\mathrm{CH}_{2}-$ bridges) making the computational procedures demanding on top of the molecular size. We performed molecular mechanics minimizations followed by DFT calculations using $\mathrm{QB} 97 \mathrm{X}$ $\mathrm{D} / 6-31 \mathrm{G}(\mathrm{d})$ and were able to reduce the possible conformers to a total of eight conformers for each of the molecules studied $\left(\mathrm{G}_{+} \mathrm{G}_{+} \mathrm{G}_{+}, \mathrm{G}_{-} \mathrm{G}_{-} \mathrm{G}_{-}, \mathrm{G}_{+} \mathrm{G}_{+} \mathrm{G}_{-}, \mathrm{G}_{-} \mathrm{G}_{-} \mathrm{G}_{+}, \mathrm{T}_{+} \mathrm{T}_{+} \mathrm{T}_{+}, \mathrm{T}_{-} \mathrm{T}_{-} \mathrm{T}_{-}, \mathrm{T}_{+} \mathrm{T}_{+} \mathrm{T}_{-}\right.$, $\mathrm{T}_{-} \mathrm{T}_{-} \mathrm{T}_{+}$) by screening out those with an energy of more than $8 \mathrm{kcal} / \mathrm{mol}$ compared to the most stable conformer in each set of molecules. For example, among the possible conformations of the empty cryptophane-A cage analysed using $\omega B 97 X-D / 6-31 G(d, p)$, the conformer with G_G_G_ is the most stable conformer followed by $\mathrm{G}_{-} \mathrm{T}_{-} \mathrm{T}_{-} 1.4 \mathrm{kcal} / \mathrm{mol}$ higher in energy, $\mathrm{G}_{+} \mathrm{G}_{+} \mathrm{G}_{+}$by $2.2 \mathrm{kcal} / \mathrm{mol}, \mathrm{G}_{-} \mathrm{G}_{-} \mathrm{G}_{+}$by $3.1 \mathrm{kcal} / \mathrm{mol}, \mathrm{T}_{-} \mathrm{T}_{-} \mathrm{T}_{-}$by $7.3 \mathrm{kcal} / \mathrm{mol}$ and $\mathrm{T}_{-} \mathrm{T}_{-} \mathrm{T}_{+}$by 7.6 $\mathrm{kcal} / \mathrm{mol}$, whereas the rest are unstable by more than $8.0 \mathrm{kcal} / \mathrm{mol}$ compared to the most stable conformer (G_G_G_). Similar analysis for the $\mathrm{CH}_{4} @$ cryptophane-A complex (shown in Figure 1) shows that the conformer with the $G_{-} G_{-} G_{+}$conformation is the most stable followed by $\mathrm{G}_{+} \mathrm{G}_{+} \mathrm{G}_{+}$by $0.6 \mathrm{kcal} / \mathrm{mol}, \mathrm{G}_{-} \mathrm{G}_{-} \mathrm{G}_{-}$by $3.0 \mathrm{kcal} / \mathrm{mol}$, and $\mathrm{T}_{-} \mathrm{T}_{-} \mathrm{T}_{+}$by $6.9 \mathrm{kcal} / \mathrm{mol}$. The other possible conformers are less stable by more than $7.0 \mathrm{kcal} / \mathrm{mol}$. 
The situation simplifies as the bridge lengths decrease. For example, the molecule with only $-\mathrm{O}-\mathrm{CH}_{2}-\mathrm{O}-$ has fewer possible conformers compared to cryptophane-A which has a -O$\mathrm{CH}_{2}-\mathrm{CH}_{2}-\mathrm{O}-$ bridge, and the bridges become less flexible when their lengths decrease (see $\mathrm{CH}_{4} @ 1$ and $\mathrm{CH}_{4} @ 3$ in Figure 1). Replacing the oxygen atoms by $\mathrm{CH}_{2}$ groups also affects the conformations in such a way that the gauche conformation of the bridges become less favourable and those with nearly trans orientations of the butylene linkers become dominant. Unlike those with $-\mathrm{O}-\mathrm{CH}_{2}-\mathrm{CH}_{2}-\mathrm{O}-$ which have both gauche and anti-conformation of the bridges, the molecules with $-\mathrm{CH}_{2}-\mathrm{CH}_{2}-\mathrm{CH}_{2}-\mathrm{CH}_{2}$ - bridges only have an anti-conformation for the bridges after geometry optimization, irrespective of the input geometry.

A previous study by Brotin et al. ${ }^{3}$ on the derivative of cryptophane-A where one methoxy substituent is replaced by hydrogen atoms (cryptophane-H), showed that the molecule prefers the gauche-conformation for the ethylene oxide linkers, in agreement with our conformational analysis for the molecules with ethylene oxide linkers. Replacing the oxygen atoms of the bridges changes the conformation of both the cages and the complexes. For instance, in both the empty and complexed cryptophane-A, all the bridges prefer the gauche-conformations unlike the molecules with all $\mathrm{CH}_{2}$ linkers. The effect of replacing the methoxy substituent by methyl has a minimal effect on the conformation of both the empty cage and the $\mathrm{CH}_{4}$ encapsulated molecules.

In addition to the conformational complexity arising from the bridges, there are two other possible conformations based on the orientation of the methoxy substituents on the rings. The first one is when the methoxy group points out of the plane of the aromatic rings, and the other is when the methoxy groups are in the plane of the aromatic rings. Calculations show that the latter is more stable by an average of $2 \mathrm{kcal} / \mathrm{mol}$ irrespective of the conformation of the bridge linkers. The calculations using $\odot B 97 X-D / 6-31 G(d, p)$ show that the anti-conformers are dominant. As most of the experimental host-guest complexes are based on the anti-conformer of cryptophane-A,,$^{3-5,62}$ we also considered only this conformation for all the molecules studied. Overall, the calculations performed using $\omega$ B97X-D for the molecules involving diastereomers, which refers to the orientation of the methoxy substituents with respect to the ethylene oxide bridges, indicated that the syn-conformers are less stable than the anticonformers. This is mainly due to steric effects, which are minimized in the anti-conformation. For instance, the syn form of cryptophane-A is less stable than the anti-conformer by 2.1 $\mathrm{kcal} / \mathrm{mol}$ in the free energy, or by $3.7 \mathrm{kcal} / \mathrm{mol}$ for $\Delta(\mathrm{E}+\mathrm{ZPE})$, in agreement with experimental studies. ${ }^{3-5,62}$ Hence, the anti-conformers identified using $\omega \mathrm{B} 97 \mathrm{X}-\mathrm{D} / 6-311 \mathrm{G}(\mathrm{d}, \mathrm{p})$ for all 
molecules with diastereomers were considered for further geometry optimizations and frequency calculations using the other six functionals. A more detailed conformational analysis is presented in the ESI.

\subsection{Methane Complexation Energies}

The change in free energy of stabilization $\left(\Delta G_{\text {stab }}\right)$, Eq. 1 , for the methane complexes calculated using different functionals are presented in Table 1 and Figure 2. The results show that the B3LYP functional without dispersion correction overestimates the stabilization free energies compared to the other functionals, and gives very different results than all the other functionals. In most of the methane complexes, the inclusion of the Becke and Johnson (BJdamping) damping function (which has the advantage of avoiding repulsive interatomic forces at shorter distances between the host and guest molecules) causes minimal effects. Of all the functionals, $\mathrm{B} 97 \mathrm{X}-\mathrm{D}$ predicted negative stabilization free energies for $\mathrm{CH}_{4} @ \mathbf{1}, \mathrm{CH}_{4} @ \mathbf{2}$, $\mathrm{CH}_{4} @ \mathbf{8}$, and $\mathrm{CH}_{4} @ \mathbf{1 0}$ (negative stabilization energy implies the presence of attractive forces between the host and guest molecules). There is experimental evidence ${ }^{20}$ for the stable complex formation of $\mathrm{CH}_{4} @ \mathbf{1}$. The experimental free energy of association $\left(\Delta G^{\circ}\right)$ has been estimated from NMR measurements by Chaffee et al ${ }^{4}$ to be $-2.70 \mathrm{kcal} / \mathrm{mol}$ for $\mathrm{CH}_{4} @$ cryptophane-A and to be $-2.9 \mathrm{kcal} / \mathrm{mol}$ by Garel et al. ${ }^{21}$ at $298 \mathrm{~K}$. Our calculations predict a highly stable complex for $\mathrm{CH}_{4} @ 8$ compared to the experimentally known $\mathrm{CH}_{4} @ 1$ (see Table 1). The M06-L functional includes dispersion correction, however, it predicts a stabilization free energy of only $-0.04 \mathrm{kcal} / \mathrm{mol}$ for the $\mathrm{CH}_{4} @ \mathbf{1}$, indicating that it is unable to sufficiently account for the weak interactions of these complexes. The overall results show the influence of dispersion corrections in these complexes, keeping in mind that the SCS-MP2 results are taken as benchmarks. ${ }^{63,64}$

The summary of the interaction and binding energies (calculated using Eq. 2 and 3) of the complexes are presented in Figures 3 and 4. From Figure 3 we see that B3LYP significantly underestimates the host-guest interactions as it predicts all positive values. The inclusion of dispersion corrections changes the sign and dramatically changes the predicted change in the interaction and binding energies. These comparisons indicate that the use of B3LYP for theoretical studies of such molecules and complexes could give strongly misleading results, and that this functional is not suitable for such calculations. There are also previous studies demonstrating that B3LYP is unable to predict complex formation energies compared to the results obtained when dispersion corrections are included. ${ }^{42,65-67}$ Compared to SCS-MP2, the 
๑B97X-D functional predicts slightly overestimated interaction energies, whereas M06-L predicts strong binding energies (see Figure 4). The inclusion of the damping function has negligible effect when compared to B3LYP-D3. This is in agreement with previous benchmark calculations..$^{42}$

The M06-L and SCS-MP2 calculated interaction-, binding- and stabilization energies for the corresponding methane complexes are presented in Table 2 (the results using the other functionals are presented in the ESI). The results show that $\mathrm{CH}_{4} @ \mathbf{8}$ is a more stable complex compared to the other complexes, followed by $\mathrm{CH}_{4} @ 1$. Our calculations predict that the novel, proposed cavitand $\mathbf{8}$, could be a promising host for improved methane binding. This is achieved by modifying the cryptophane cage with hydrocarbon linkers (only $-\mathrm{CH}_{2}-$ ), and by substituting the methoxy groups with methyl groups. The SCS-MP2 calculated cage deformation energy of $\mathrm{CH}_{4} @ 8(-2.38 \mathrm{kcal} / \mathrm{mol}$, where the deformed cages have smaller total energy than the uncomplexed cages) demonstrates the strong interaction between the host $\mathbf{8}$ and its guest molecule (Table 2). This is followed by $\mathrm{CH}_{4} @ \mathbf{1}$ and $\mathrm{CH}_{4} @ \mathbf{3}$, and thus represents a potential improvement in binding properties compared to the established cavitand 1. Comparing complexes $\mathrm{CH}_{4} @ 5-\mathrm{CH}_{4} @ \mathbf{1 0}$, the cage deformation energy decreases as the length of the linkers increases, showing decreased interaction between the host and the guest. For instance, the cage deformation energy calculated using M06- $\mathrm{L}$ for $\mathrm{CH}_{4} @ 5$ (only two carbon linkers) is $-2.38 \mathrm{kcal} / \mathrm{mol}$, whereas it is $-0.35 \mathrm{kcal} / \mathrm{mol}$ for $\mathrm{CH}_{4} @ 9$ (four carbon linkers). In most cases, the SCS-MP2 calculated interaction and binding energies are smaller than those obtained using M06-L. The results presented in Table 2 also show the presence of relatively strong interactions between the host and guest for $\mathrm{CH}_{4} @ \mathbf{1}, \mathrm{CH}_{4} @ \mathbf{2}, \mathrm{CH}_{4} @ \mathbf{4}$ and $\mathrm{CH}_{4} @ \mathbf{8}$. The stabilization energy calculated using Eq. 3 predicts that $\mathrm{CH}_{4} @ \mathbf{6}$ is the least stable complex, whereas $\mathrm{CH}_{4} @ \mathbf{8}$ is the most stable of all the ten complexes (see Figure 5 for the summarized overall results).

\subsection{Xenon Complexation Energies}

The stabilization free energies for the Xe@cryptophane complexes calculated using different functionals are presented in Table 3. As is the case for the methane complexes, B3LYP predicts all complexes to be unstable. However, the results change with the inclusion of dispersion corrections. For instance, B3LYP predicts a stabilization free energy of 12.34 $\mathrm{kcal} / \mathrm{mol}$ for Xe@1, whereas B3LYP-D3 predicts -3.75 kcal/mol. The addition of the BJdamping correction further strengthens the predicted stabilization free energies. B3LYP-D3 and B3LYP-D3BJ predicts Xe@8 to be the most stable complex followed by Xe@1. The 
$\omega \mathrm{B} 97 \mathrm{X}-\mathrm{D}$ functional predicts Xe@1 to be the most stable complex followed by Xe@8. Similarly, M06-L predictsXe@1 to be the most stable complex followed by Xe@2 and Xe@3. On the other hand, all the functionals predict that Xe@5 and Xe@6 are unstable complexes (note that $\mathbf{5}$ and $\mathbf{6}$ only have two carbon linkers), indicating that the volume of the cage is not sufficiently large to host the guest without imposing structural strain. For Xe@1 - Xe@4, replacing the methoxy side groups by methyl decreases the stability of the complexes (see Table 3), whereas the reverse trend is observed in most cases for the complexes of Xe@7 Xe@10.

The complexation energies for the xenon complexes calculated using Eqs. 1 and 2 are presented in Table 4. From the cage deformation energies we see that the cryptophanes with shorter bridges are deformed considerably compared to the other complexes. For instance, $E_{\text {deform }}$ for Xe@5 and Xe@6 (with only two carbon linkers) are -2.07 kcal/mol and -3.06 $\mathrm{kcal} / \mathrm{mol}$, respectively, whereas they are $-0.73 \mathrm{kcal} / \mathrm{mol}$ and $-0.24 \mathrm{kcal} / \mathrm{mol}$, respectively, for Xe@9 and Xe@10. The interaction energies are also in agreement with the cage deformation energies, those with short bridges having smaller interaction energies. The M06-L calculated binding energies predicted that xenon can bind strongly to 7 and $\mathbf{8}$. However, SCS-MP2 predicted that the binding of xenon to 4 is stronger, followed by $\mathbf{7}$. The stabilization energies calculated using M06-L also predicted that complexes Xe@7 and Xe@8 are the most stable, followed byXe@1 andXe@3. SCS-MP2 predictedXe@4 to be the most stable complex followed by Xe@7. The overall analysis of the results shows that cages $\mathbf{7}$ and $\mathbf{8}$ are the best in forming stable complexes with xenon.

\section{4. $\quad{ }^{13} \mathrm{C}$ and ${ }^{129} \mathrm{Xe}$ NMR Chemical Shifts}

NMR chemical shifts give insight on how the guest molecules interact with the host. In addition, since the hyperpolarized guest xenon is used in biosensing ${ }^{24,25}$ and magnetic resonance imaging (MRI), ${ }^{26,27}$ the chemical shifts are also important in order to study the sensitivity of xenon when complexed with the hosts. The measurement of chemical shifts of ${ }^{129} \mathrm{Xe}$ is used to monitor its binding to cryptophane cages, and also to determine molecular affinities. ${ }^{13,68,69}$ Considering this, and to assist peak assignment of bound guests, we calculated the ${ }^{13} \mathrm{C}$ and ${ }^{129} \mathrm{Xe}$ chemical shifts for the complexes, listed in Table 5. The gas phase and solvent (water) calculated ${ }^{129} \mathrm{Xe}$ chemical shifts show considerable solvent effects. With the exception of Xe@1 and Xe@9, the chemical shifts are downfield relative to the signal of free xenon. The strongest solvent effect is observed for Xe@1,with a change of 37\%. 
It is commonly assumed that all known Xe@cryptophane complexes resonate in the ${ }^{129} \mathrm{Xe}$ frequency range of $30-80 \mathrm{ppm}$ near room temperature. ${ }^{7}$ However, the results listed in Table 5 show that complexes $\mathbf{5}$ and $\mathbf{6}$, where the bridges are replaced by all-carbon atoms, resonate at much higher frequencies of $189 \mathrm{ppm}$ and $177 \mathrm{ppm}$, respectively, when calculated in gas phase. The shifts calculated in water are also higher than the other complexes. Complexes $\mathbf{7}$ and $\mathbf{8}$ are found to be the best candidates for the formation of stable complexes with improved binding with both methane and xenon. The calculated ${ }^{129} \mathrm{Xe}$ chemical shifts for these complexes are higher than that of the known complex Xe@1. For instance, the calculated (in gas phase) chemical shift for Xe@8 is 102.8 ppm, whereas that of Xe@1 is 55.5 ppm. Since most of the hosts have not yet been synthesized, we were unable to compare the calculated chemical shifts with the corresponding experimental values. However, Xe@1 is a known complex with ${ }^{129} \mathrm{Xe}$ chemical shift of $63 \mathrm{ppm}^{7}$ measured in $1,1,2,2-\mathrm{C}_{2} \mathrm{H}_{2} \mathrm{Cl}_{4}$ and referenced to gaseous xenon, to be compared with our calculated values of $55.5 \mathrm{ppm}$ in gas phase and 87.7 ppm in water. Even though it is not the focus of our study, we considered Xe@cryptophane111 (where all the methoxy side attachments of Xe@3 are replaced by hydrogens) to validate our calculations. For this complex we found a ${ }^{129} \mathrm{Xe}$ chemical shift of $38 \mathrm{ppm}$ in gas phase, which is in fair agreement with the experimental value of $31 \mathrm{ppm}$ measured in $1,1,2,2-\mathrm{C}_{2} \mathrm{H}_{2} \mathrm{Cl}_{4}$ and referenced to gaseous xenon. ${ }^{7}$

The ${ }^{13} \mathrm{C}$ and ${ }^{1} \mathrm{H}$ chemical shifts are also sensitive to the change in the structures of the cages. As the length of the linkers increases (see $\mathrm{CH}_{4} @ \mathbf{5}-\mathrm{CH}_{4} @ \mathbf{1 0}$ ), the carbon chemical shifts move upfield whereas the proton chemical shifts are shifted downfield (see Table 5). These changes are important for specific detection of methane by varying the length of the linkers. The chemical shifts are also sensitive with respect to replacing the methoxy side groups with methyl. For instance, the ${ }^{13} \mathrm{C}$ chemical shift of $\mathrm{CH}_{4} @ \mathbf{1}$ (with methoxy side groups) is 5.81 ppm, whereas that of $\mathrm{CH}_{4} @ 2$ (with methyl side groups) is -7.47 ppm. For the purpose of validation of the method, we calculated the ${ }^{1} \mathrm{H}$ chemical shift for $\mathrm{CH}_{4} @$ cryptophane-111 (where all the methoxy side groups of $\mathrm{CH}_{4} @ 3$ are replaced by hydrogen atoms) and obtained $-5.2 \mathrm{ppm}$ which is to be compared with the corresponding experimental value of $-5.3 \mathrm{ppm},{ }^{4}$ confirming that our calculated results represent well the chemical shifts of the complexes we studied.

\section{Conclusions}


In this work, we have conducted conformational analyses of several known and newly proposed cryptophane-like host molecules and their corresponding $\mathrm{CH}_{4}$ and $\mathrm{Xe}$ complexes to the identify the most stable structures using DFT and SCS-MP2 methods. For the most stable conformers, we have analysed the stabilization, interaction, and binding energies of the complexes, as well as NMR chemical shifts. We have sought to demonstrate the power and limitations of the computational methods in exploring binding and NMR-properties of both established and novel host systems. The ultimate goal has been to establish computational tools that enable the accurate prediction of new host molecules with enhanced methane and xenon complexation properties. Both guests are highly relevant in the development of sensors for medical and environmental applications. The calculations performed using B3LYP and B3LYP-D3BJ show the importance of the inclusion of dispersion corrections to the DFT functional. The overall analysis of the dispersion corrections indicated that results obtained from pure B3LYP should be used cautiously when drawing conclusions, and it is not advisable to use this functional without the appropriate corrections when the system under study has considerable weak interactions. Based on this study, we recommend the M06-L and $\omega B$ 97XD functionals for the computational study of such inclusion complexes. However, we note that other dispersion corrected functionals may outperform these two DFT functionals based on the nature of the molecular systems studied. ${ }^{44,70}$ Proposed derivatives of cryptophane-A, where the alkoxy bridges are replaced by alkyl chains ( $\mathbf{7}$ and $\mathbf{8}$ ), are predicted to display enhanced affinity towards both methane and xenon.

\section{ASSOCIATED CONTENT}

\section{Supporting Information}

The Supporting Information is available free of charge on the ACS Publications website at DOI: $10.1021 /$ acs.jpca.xxxxx

\section{AUTHOR INFORMATION}

\section{Corresponding Author}

*(J.H.H.) E-mail: jorn.h.hansen@uit.no

Notes

The authors declare no competing financial interest. 
This work has received support from the Research Council of Norway [grant no. 179568] (T.B.D and K.R.), and the Department of Chemistry at UiT The Arctic University of Norway (T.B.D, K.R. and J.H.H). Computer time was provided by the Norwegian supercomputing program NOTUR [grant no. NN4654K].

\section{References}

(1) Gabard, J.; Collet, A. Synthesis of a (D3)-bis(cyclotriveratrylenyl) Macrocage by Stereospecific Replication of a (C3)-Subunit. J. Chem. Soc., Chem. Commun., 1981, 11371139.

(2) Taratula, O.; Hill, P. A.; Khan, N. S.; Carroll, P. J.; Dmochowski, I. J. Crystallographic Observation of 'Induced Fit' in A Cryptophane Host-Guest Model System. Nat. Commun. 2010, 1, 148.

(3) Brotin, T.; Cavagnat, D.; Buffeteau, T. Conformational Changes in Cryptophane Having C1-Symmetry Studied by Vibrational Circular Dichroism. J. Phys. Chem. A 2008, 112, 8464-8470.

(4) Chaffee, K. E.; Fogarty, H. A.; Brotin, T.; Goodson, B. M.; Dutasta, J.-P. Encapsulation of Small Gas Molecules by Cryptophane-111 in Organic Solution. 1. Size- and Shape-Selective Complexation of Simple Hydrocarbons. J. Phys. Chem. A 2009, 113, 1367513684.

(5) Brotin, T.; Dutasta, J.-P. Cryptophanes and Their Complexes - Present and Future. Chem. Rev. 2009, 109, 88-130.

(6) Brotin, T.; Lesage, A.; Emsley, L.; Collet, A. 129Xe NMR Spectroscopy of Deuterium-Labeled Cryptophane-A Xenon Complexes: Investigation of Host-Guest Complexation Dynamics. J. Am. Chem. Soc. 2000, 122, 1171-1174.

(7) Fairchild, R. M.; Joseph, A. I.; Holman, K. T.; Fogarty, H. A.; Brotin, T.; Dutasta, J.P.; Boutin, C.; Huber, G.; Berthault, P. A Water-Soluble Xe@cryptophane-111 Complex Exhibits Very High Thermodynamic Stability and a Peculiar 129Xe NMR Chemical Shift. J. Am. Chem. Soc. 2010, 132, 15505-15507.

(8) Gao, L.; Liu, W.; Lee, O.-S.; Dmochowski, I. J.; Saven, J. G. Xe Affinities of WaterSoluble Cryptophanes and the Role of Confined Water. Chem. Sci. 2015, 6, 7238-7248.

(9) Chen, Y.; Pang, Y.; Wu, J.; Su, Y.; Liu, J.; Wang, R.; Zhu, B.; Yao, Y.; Yan, D.; Zhu, X.; Chen, Q. Controlling the Particle Size of Interpolymer Complexes through Host-Guest Interaction for Drug Delivery. Langmuir 2010, 26, 9011-9016. 
(10) Spence, M. M.; Rubin, S. M.; Dimitrov, I. E.; Ruiz, E. J.; Wemmer, D. E.; Pines, A.; Yao, S. Q.; Tian, F.; Schultz, P. G. Functionalized Xenon as a Biosensor. Proc. Natl. Acad. Sci.U.S.A. 2001, 98, 10654-10657.

(11) Benounis, M.; Jaffrezic-Renault, N.; Dutasta, J. P.; Cherif, K.; Abdelghani, A. Study of a New Evanescent Wave Optical Fibre Sensor For Methane Detection Based on Cryptophane Molecules. Sens. Actuator B-Chem. 2005, 107, 32-39.

(12) Marjanska, M.; Goodson, B. M.; Castiglione, F.; Pines, A. Inclusion Complexes Oriented in Thermotropic Liquid-Crystalline Solvents Studied with Carbon-13 NMR. J. Phys. Chem. B 2003, 107, 12558-12561.

(13) Taratula, O.; Dmochowski, I. J. Functionalized 129Xe Contrast Agents for Magnetic Resonance Imaging. Curr. Opin. Chem. Biol. 2010, 14, 97-104.

(14) Bartik, K.; Luhmer, M.; Dutasta, J.-P.; Collet, A.; Reisse, J. 129Xe and 1H NMR Study of the Reversible Trapping of Xenon by Cryptophane-A in Organic Solution. J. Am. Chem. Soc. 1998, 120, 784-791.

(15) Seward, G. K.; Bai, Y.; Khan, N. S.; Dmochowski, I. J. Cell-Compatible, IntegrinTargeted Cryptophane-129Xe NMR Biosensors. Chem. Sci. 2011, 2, 1103-1110.

(16) Khan, N. S.; Riggle, B. A.; Seward, G. K.; Bai, Y.; Dmochowski, I. J. CryptophaneFolate Biosensor for 129Xe NMR. Bioconjugate Chem. 2015, 26, 101-109.

(17) Clever, H. L. Solubility Data Series Volume 2 IUPAC, Ed. Online 1979.

(18) Dubost, E.; Dognon, J.-P.; Rousseau, B.; Milanole, G.; Dugave, C.; Boulard, Y.; Léonce, E.; Boutin, C.; Berthault, P. Understanding a Host-Guest Model System through 129Xe NMR Spectroscopic Experiments and Theoretical Studies. Angew. Chem. Int. Ed. 2014, $53,9837-9840$.

(19) Boulart, C.; Mowlem, M. C.; Connelly, D. P.; Dutasta, J.-P.; German, C. R. A Novel, Low-Cost, High Performance Dissolved Methane Sensor for Aqueous Environments. Opt. Express 2008, 16, 12607-12617.

(20) Dullo, F. T.; Lindecrantz, S.; Jágerská, J.; Hansen, J. H.; Engqvist, M.; Solbø, S. A.; Hellesø, O. G. Sensitive on-Chip Methane Detection with a Cryptophane-A Cladded MachZehnder Interferometer. Opt. Express 2015, 23, 31564-31573.

(21) Garel, L.; Dutasta, J.-P.; Collet, A. Complexation of Methane and Chlorofluorocarbons by Cryptophane-A in Organic Solution. Angew. Chem. Int. Ed. 1993, 32, 1169-1171. 
(22) Canceill, J.; Collet, A.; Gottarelli, G.; Palmieri, P. Synthesis and Exciton Optical Activity of D3-Cryptophanes. J. Am. Chem. Soc. 1987, 109, 6454-6464.

(23) Brotin, T.; Daugey, N.; Vanthuyne, N.; Jeanneau, E.; Ducasse, L.; Buffeteau, T. Chiroptical Properties of Cryptophane-223 and -233 Investigated by ECD, VCD, and ROA Spectroscopy. J. Phys. Chem. B 2015, 119, 8631-8639.

(24) Lowery, T. J.; Garcia, S.; Chavez, L.; Ruiz, E. J.; Wu, T.; Brotin, T.; Dutasta, J.-P.; King, D. S.; Schultz, P. G.; Pines, A.; Wemmer, D. E. Optimization of Xenon Biosensors for Detection of Protein Interactions. ChemBioChem 2006, 7, 65-73.

(25) Wang, Y.; Dmochowski, I. J. An Expanded Palette of Xenon-129 NMR Biosensors. Acc. Chem. Res. 2016, 49, 2179-2187.

(26) Zhou, X.; Graziani, D.; Pines, A. Hyperpolarized Xenon NMR and MRI Signal Amplification by Gas Extraction. Proc. Natl. Acad. Sci. U.S.A. 2009, 106, 16903-16906.

(27) Ana-Maria, O.; Shah, N. J. Hyperpolarized Xenon in NMR and MRI. Phys. Med. Biol. 2004, 49, R105.

(28) Grimme, S. Improved Second-Order Møller-Plesset Perturbation Theory by Separate Scaling of Parallel- and Antiparallel-Spin Pair Correlation Energies. J. Chem. Phys. 2003, 118, 9095-9102.

(29) Canceill, J.; Cesario, M.; Collet, A.; Guilhem, J.; Riche, C.; Pascard, C. Selective Recognition of Neutral Molecules: 1H N.M.R. Study of the Complexation of $\mathrm{CH} 2 \mathrm{Cl} 2$ And $\mathrm{CH} 2 \mathrm{Br} 2$ by Cryptophane-D in Solution and Crystal Structure of its $\mathrm{CH} 2 \mathrm{Cl} 2$ Cavitate. J. Chem. Soc., Chem. Commun. 1986, 339-341.

(30) Joseph, A. I.; Lapidus, S. H.; Kane, C. M.; Holman, K. T. Extreme Confinement of Xenon by Cryptophane-111 in the Solid State. Angew. Chem. Int. Ed. 2015, 54, 1471-1475.

(31) Marvin 15.11.23 MarvinView 15.11.23 ed.; ChemAxon (http://www.chemaxon.com), 2015.

(32) PCModel. Pcmodel version 9.0; Version 9.0, Serena Software (http://www.serenasoft.com/).

(33) Chai, J.-D.; Head-Gordon, M. Long-Range Corrected Hybrid Density Functionals with Damped Atom-Atom Dispersion Corrections. Phys. Chem. Chem. Phys. 2008, 10, 66156620.

(34) Krishnan, R.; Binkley, J. S.; Seeger, R.; Pople, J. A. Self-Consistent Molecular Orbital Methods. XX. A Basis Set for Correlated Wave Functions. J. Chem. Phys. 1980, 72, 650-654. 
(35) Buffeteau, T.; Pitrat, D.; Daugey, N.; Calin, N.; Jean, M.; Vanthuyne, N.; Ducasse, L.; Wien, F.; Brotin, T. Chiroptical Properties of Cryptophane-111. Phys. Chem. Chem. Phys. 2017, 19, 18303-18310.

(36) Weigend, F.; Ahlrichs, R. Balanced Basis Sets Of Split Valence, Triple Zeta Valence and Quadruple Zeta Valence Quality for H to Rn: Design and Assessment of Accuracy. Phys. Chem. Chem. Phys. 2005, 7, 3297-3305.

(37) Simeon, T. M.; Ratner, M. A.; Schatz, G. C. Nature of Noncovalent Interactions in Catenane Supramolecular Complexes: Calibrating the MM3 Force Field with ab Initio, DFT, and SAPT Methods. J. Phys. Chem. A 2013, 117, 7918-7927.

(38) Dodziuk, H.; Ruud, K.; Korona, T.; Demissie, T. B. Chiral Recognition by Fullerenes: CHFClBr Enantiomers in the C82 Cage. Phys. Chem. Chem. Phys. 2016, 18, 26057-26068.

(39) Lee, C.; Yang, W.; Parr, R. G. Development of the Colle-Salvetti Correlation-Energy Formula into A Functional of the Electron Density. Phys. Rev. B 1988, 37, 785-789.

(40) Stephens, P. J.; Devlin, F. J.; Chabalowski, C. F.; Frisch, M. J. Ab Initio Calculation of Vibrational Absorption and Circular Dichroism Spectra Using Density Functional Force Fields. J. Phys. Chem. 1994, 98, 11623-11627.

(41) Becke, A. D. Density-Functional Thermochemistry. III. The Role of Exact Exchange. J. Chem. Phys. 1993, 98, 5648-5652.

(42) Grimme, S.; Ehrlich, S.; Goerigk, L. Effect of the Damping Function in Dispersion Corrected Density Functional Theory. J. Comput. Chem. 2011, 32, 1456-1465.

(43) Zhao, Y.; Truhlar, D. G. A New Local Density Functional for Main-Group Thermochemistry, Transition Metal Bonding, Thermochemical Kinetics, and Noncovalent Interactions. J. Chem. Phys. 2006, 125, 194101.

(44) Wong, B. M. Noncovalent Interactions in Supramolecular Complexes: A Study on Corannulene and The Double Concave Buckycatcher. J. Comput. Chem. 2009, 30, 51-56.

(45) Takatani, T.; David Sherrill, C. Performance of spin-component-scaled MollerPlesset theory (SCS-MP2) for potential energy curves of noncovalent interactions. Phys. Chem. Chem. Phys. 2007, 9, 6106-6114.

(46) Frisch, M. J.; Trucks, G. W.; Schlegel, H. B.; Scuseria, G. E.; Robb, M. A.; Cheeseman, J. R.; Montgomery Jr., J. A.; Vreven, T.; Kudin, K. N.; Burant, J. C.; Millam, J. M.; Lyengar, S. S.; Tomasi, J.; Barone, V.; Mennucci, B.; Cossi, M.; Scalmani, G.; Rega, N.; Petersson, G. A.; Nakatsuji, H.; Hada, M.; Ehara, M.; Toyota, K.; Fukuda, R.; Hasegawa, J.; Ishida, M.; Nakajima, T.; Honda, Y.; Kitao, O.; Nakai, H.; Klene, M.; Li, X.; Knox, J. E.; 
Hratchian, H. P.; Cross, J. B.; Bakken, V.; Adamo, C.; Jaramillo, J.; Gomperts, R.; Stratmann, R. E.; Yazyev, O.; Austin, A. J.; Cammi, R.; Pomelli, C.; Ochterski, J. W.; Ayala, P. Y.; Morokuma, K.; Voth, G. A.; Salvador, P.; Dannenberg, J. J.; Zakrzewski, V. G.; Dapprich, S.; Daniels, A. D.; Strain, M. C.; Farkas, O.; Malick, D. K.; Rabuck, A. D.; Raghavachari, K.; Foresman, J. B.; Ortiz, J. V.; Cui, Q.; Baboul, A. G.; Clifford, S.; Cioslowski, J.; Stefanov, B. B.; Liu, G.; Liashenko, A.; Piskorz, P.; Komaromi, I.; Martin, R. L.; Fox, D. J.; Keith, T.; AlLaham, M. A.; Peng, C. Y.; Nanayakkara, A.; Challacombe, M.; Gill, P. M. W.; Johnson, B.; Chen, W.; Wong, M. W.; Gonzalez, C.; Pople, J. A. Gaussian 09; Revision C.02 ed. ed.; Gaussian, Inc.: Wallingford CT, 2009.

(47) Cancès, E.; Mennucci, B.; Tomasi, J. A New Integral Equation Formalism for the Polarizable Continuum Model: Theoretical Background and Applications to Isotropic and Anisotropic Dielectrics. J. Chem. Phys. 1997, 107, 3032-3041.

(48) Mennucci, B.; Tomasi, J. Continuum Solvation Models: A New Approach to The Problem of Solute's Charge Distribution and Cavity Boundaries. J. Chem. Phys. 1997, 106, $5151-5158$.

(49) Tomasi, J.; Mennucci, B.; Cammi, R. Quantum Mechanical Continuum Solvation Models. Chem. Rev. 2005, 105, 2999-3094.

(50) TURBOMOLE. TURBOMOLE V6.4 2012, a development of University of Karlsruhe and Forschungszentrum Karlsruhe GmbH Karlsruhe, 2012.

(51) Dodziuk, H.; Korona, T.; Lomba, E.; Bores, C. Endohedral Fullerene Complexes: Which and How Many Guests Can be Inserted in C50H10 Nanotube? J. Chem. Theor. Comp. 2012, 8, 4546-4555.

(52) Korona, T.; Hesselmann, M.; Dodziuk, H. Symmetry-Adapted Perturbation Theory Applied to Endohedral Fullerene Complexes: A Stability Study of H2@C60 and 2H2@C60. J. Chem. Theory Comp. 2009, 5, 1585-1596.

(53) Boys, S. F.; Bernardi, F. The Calculation of Small Molecular Interactions by the Differences of Separate Total Energies. Some Procedures With Reduced Errors. Mol. Phys. $1970,19,553-566$.

(54) Lenthe, E. v.; Baerends, E. J.; Snijders, J. G. Relativistic Total Energy Using Regular Approximations. J. Chem. Phys. 1994, 101, 9783-9792.

(55) Lenthe, E. v.; Ehlers, A.; Baerends, E.-J. Geometry Optimizations in the Zero Order Regular Approximation for Relativistic Effects. J. Chem. Phys. 1999, 110, 8943-8953. 
(56) Van Lenthe, E.; Baerends, E. J. Optimized Slater-Type Basis Sets for The Elements 1-118. J. Comput. Chem. 2003, 24, 1142-1156.

(57) ADF, SCM, Theoretical Chemistry, Vrije Universiteit, Amsterdam, The Netherlands, http://www.scm.com.; ADF, SCM, Theoretical Chemistry, Vrije Universiteit, Amsterdam, The Netherlands, http://www.scm.com., 2016.

(58) Bagno, A.; Saielli, G. Understanding the Extraordinary Deshielding of 129Xe in a Permetallated Cryptophane by Relativistic DFT. Chem. Eur. J. 2012, 18, 7341-7345.

(59) Wolinski, K.; Hinton, J. F.; Pulay, P. Efficient Implementation of The GaugeIndependent Atomic Orbital Method for NMR Chemical Shift Calculations. J. Am. Chem. Soc. $1990,112,8251-8260$.

(60) Demissie, T. B.; Kostenko, N.; Komorovsky, S.; Repisky, M.; Isaksson, J.; Bayer, A.; Ruud, K. Experimental and Four-Component Relativistic DFT Studies of Tungsten Carbonyl Complexes. J. Phys. Org. Chem. 2015, 28, 723-731.

(61) Forsyth, D. A.; Sebag, A. B. Computed 13C NMR Chemical Shifts via Empirically Scaled GIAO Shieldings and Molecular Mechanics Geometries. Conformation and Configuration from 13C Shifts. J. Am. Chem. Soc. 1997, 119, 9483-9494.

(62) Takacs, Z.; Steiner, E.; Kowalewski, J.; Brotin, T. NMR Investigation of Chloromethane Complexes of Cryptophane-A and Its Analogue with Butoxy Groups. J. Phys. Chem. B 2014, 118, 2134-2146.

(63) Wilson, A. K.; Thom H. Dunning, J. Benchmark Calculations With Correlated Molecular Wave Functions. X. Comparison With "Exact" MP2 Calculations on Ne, HF, H2O, and N2. J. Chem. Phys. 1997, 106, 8718-8726.

(64) Jurecka, P.; Sponer, J.; Cerny, J.; Hobza, P. Benchmark Database of Accurate (MP2 And CCSD(T) Complete Basis Set Limit) Interaction Energies of Small Model Complexes, DNA Base Pairs, and Amino Acid Pairs. Phys. Chem. Chem. Phys. 2006, 8, 1985-1993.

(65) Mardirossian, N.; Head-Gordon, M. How Accurate Are the Minnesota Density Functionals for Noncovalent Interactions, Isomerization Energies, Thermochemistry, and Barrier Heights Involving Molecules Composed of Main-Group Elements? J. Chem. Theory Comp. 2016, 12, 4303-4325.

(66) Witte, J.; Mardirossian, N.; Neaton, J. B.; Head-Gordon, M. Assessing DFT-D3 Damping Functions Across Widely Used Density Functionals: Can We Do Better? J. Chem. Theory Comp. 2017, 13, 2043-2052. 
(67) Bryantsev, V. S.; Diallo, M. S.; van Duin, A. C. T.; Goddard, W. A. Evaluation of B3LYP, X3LYP, and M06-Class Density Functionals for Predicting the Binding Energies of Neutral, Protonated, and Deprotonated Water Clusters. J . Chem. Theory Comp. 2009, 5, 10161026.

(68) Bai, Y.; Wang, Y.; Goulian, M.; Driks, A.; Dmochowski, I. J. Bacterial Spore Detection and Analysis Using Hyperpolarized 129Xe Chemical Exchange Saturation Transfer (Hyper-CEST) NMR. Chem. Rev. 2014, 5, 3197-3203.

(69) Taratula, O.; Bai, Y.; D'Antonio, E. L.; Dmochowski, I. J. Enantiopure Cryptophane129Xe Nuclear Magnetic Resonance Biosensors Targeting Carbonic Anhydrase. Supramol. Chem. 2015, 27, 65-71.

(70) Grimme, S.; Antony, J.; Schwabe, T.; Muck-Lichtenfeld, C. Density Functional Theory with Dispersion Corrections for Supramolecular Structures, Aggregates, and Complexes of (Bio)Organic Molecules. Org. Biomol. Chem. 2007, 5, 741-758. 

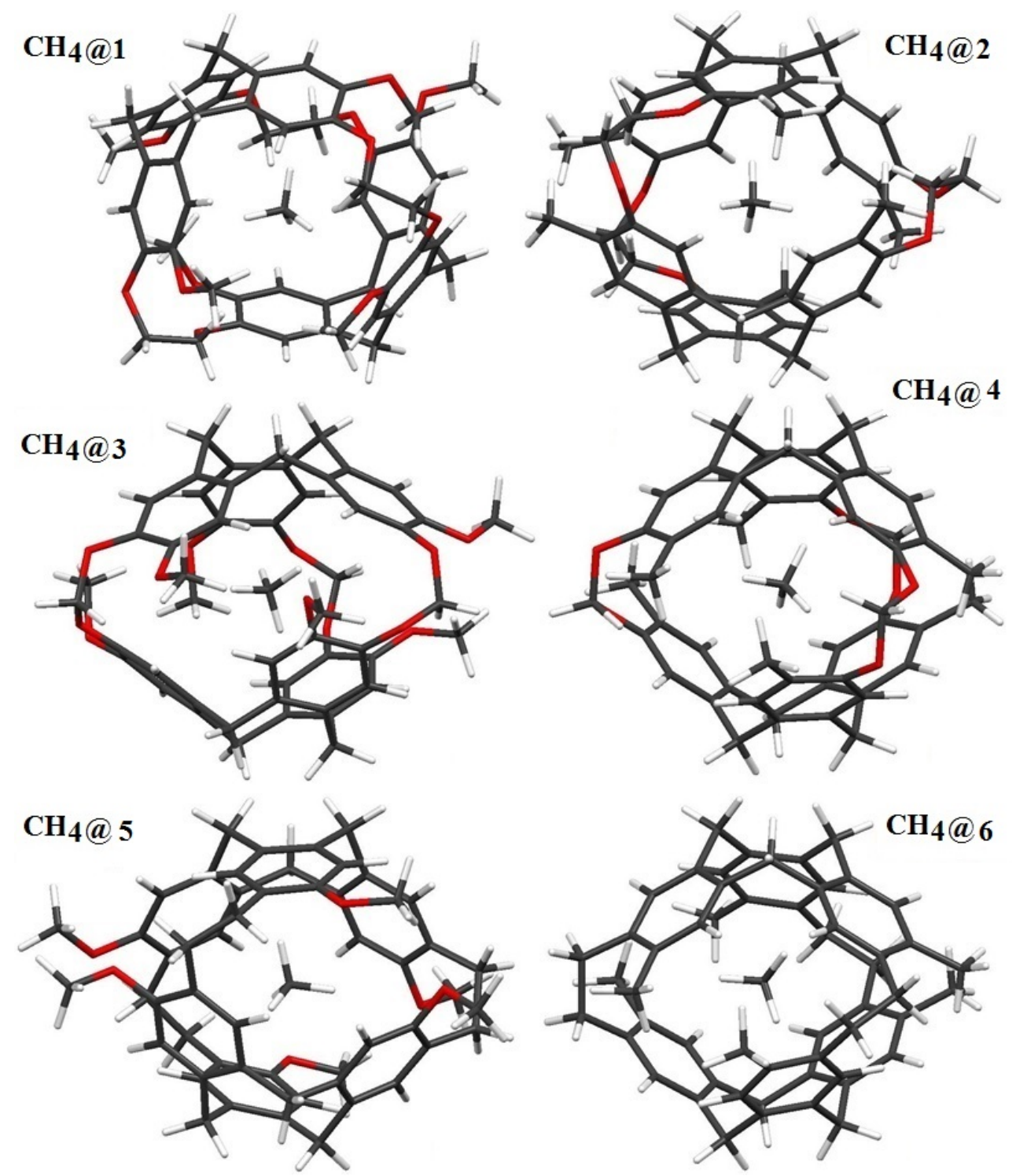

Figure 1. Optimized structures of the most stable conformers of $\mathrm{CH}_{4} @ \mathbf{1}-\mathrm{CH}_{4} @ \mathbf{6}$. 
Table 1. Comparison of the stabilization energies $\left(\Delta G_{\text {stab }}\right)$ (all in $\mathrm{kcal} / \mathrm{mol}$ ) of the $\mathrm{CH}_{4} @$ cryptophane complexes calculated using different functionals.

\begin{tabular}{|c|c|c|c|c|c|}
\hline $\mathrm{CH}_{4} @$ & B3LYP & B3LYP-D3 & B3LYP-D3BJ & $\omega$ B97X-D & M06-L \\
\hline $\mathbf{1}$ & 10.44 & 0.65 & -0.47 & -1.25 & -0.04 \\
\hline $\mathbf{2}$ & 10.15 & 0.96 & 2.05 & -0.67 & 0.54 \\
\hline $\mathbf{3}$ & 10.50 & 1.51 & 1.24 & 0.26 & 2.05 \\
\hline $\mathbf{4}$ & 12.90 & 1.76 & 0.88 & 1.51 & 3.64 \\
\hline $\mathbf{5}$ & 18.59 & 5.75 & 4.03 & 2.27 & 3.75 \\
\hline $\mathbf{6}$ & 18.86 & 5.26 & 5.42 & 3.50 & 4.04 \\
\hline $\mathbf{7}$ & 13.54 & 3.74 & 3.42 & 0.45 & 2.71 \\
\hline $\mathbf{8}$ & 16.20 & 0.90 & 3.21 & -4.66 & 2.82 \\
\hline $\mathbf{9}$ & 8.60 & 1.18 & 1.15 & 1.25 & 2.19 \\
\hline $\mathbf{1 0}$ & 8.37 & 1.65 & 1.04 & -0.10 & 1.98 \\
\hline
\end{tabular}

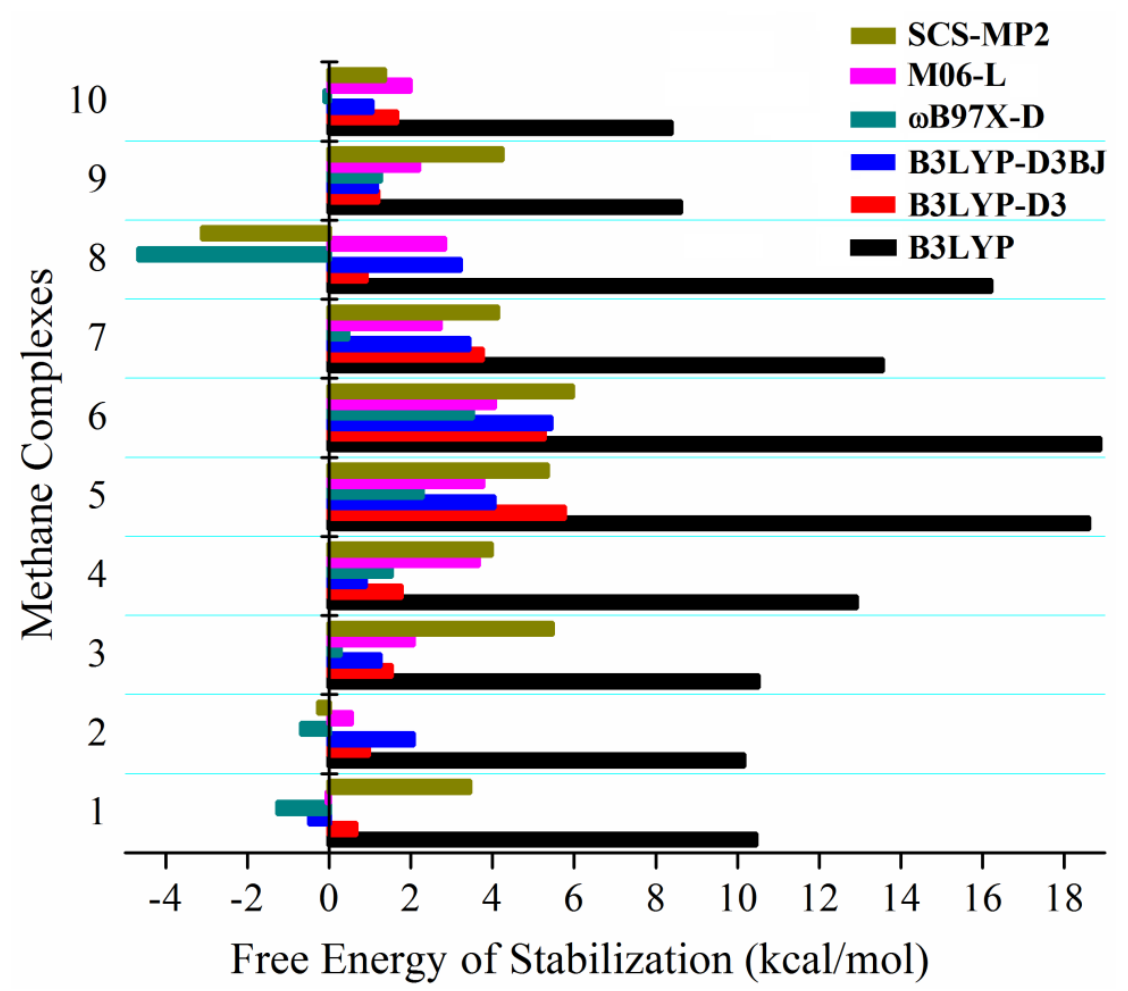

Figure 2. The free energies (calculated analogously to Eq. 1) of stabilization for the $\mathrm{CH}_{4} @$ cryptophane complexes calculated using different functionals. 


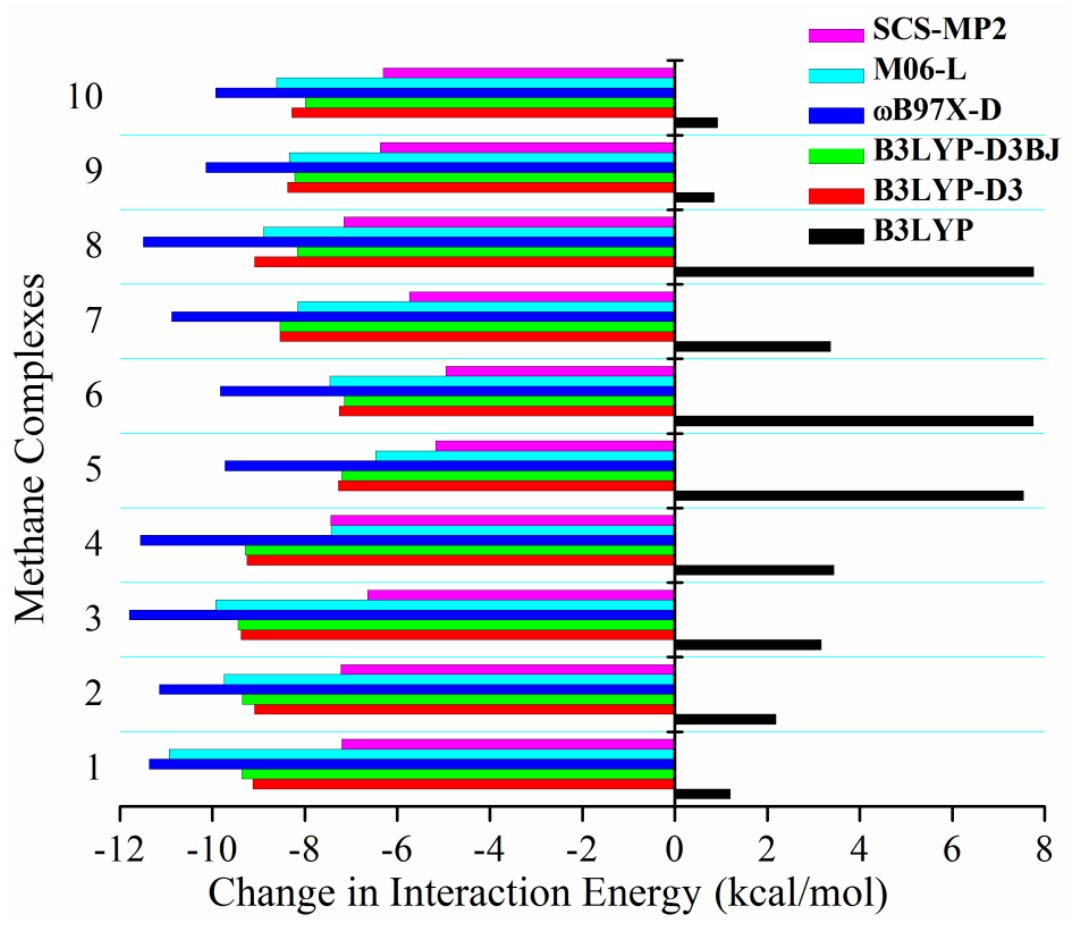

Figure 3. Interaction energies of the $\mathrm{CH}_{4} @$ cryptophane complexes calculated using different functionals.

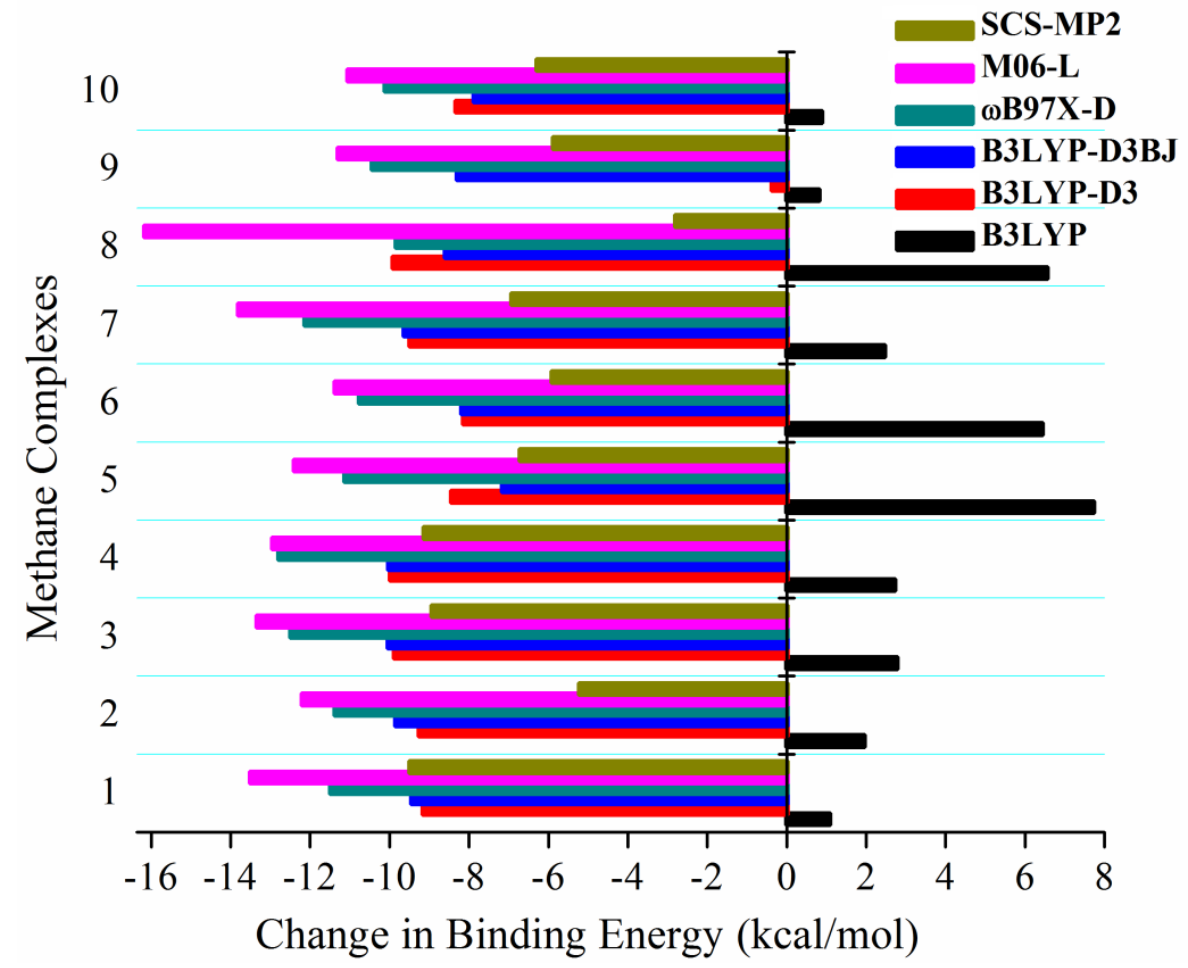

Figure 4. Binding energies of the $\mathrm{CH}_{4} @$ cryptophane complexes calculated using different functionals. 
Table 2. The cage deformation $\left(E_{\text {deform }}\right)$, interaction $\left(E_{\text {int }}\right)$, binding $\left(\Delta E_{\text {bind }}\right)$, zero-point vibrational $\left(\Delta E_{\mathrm{ZPVE}}\right)$, and stabilization energies $\left(\Delta E_{\mathrm{stab}}\right)$ (all in $\mathrm{kcal} / \mathrm{mol}$ ) of the $\mathrm{CH}_{4} @$ cryptophane complexes calculated using M06-L/6-311G(d,p) (without parenthesis) and SCS-MP2/cc-pVDZ (in parenthesis).

\begin{tabular}{|c|c|c|c|c|c|}
\hline $\mathrm{CH}_{4} @$ & $\Delta E_{\text {deform }}$ & $\Delta E_{\text {bind }}$ & $\Delta E_{\text {int }}$ & $\Delta E_{(\mathrm{ZPVE})}{ }^{\mathrm{a}}$ & $\Delta E_{\text {stab }}$ \\
\hline $\mathbf{1}$ & $-0.21(-2.27)$ & $-13.50(-9.49)$ & $-13.27(-7.20)$ & $-11.01(-3.13)$ & $-11.47(-7.71)$ \\
\hline $\mathbf{2}$ & $-0.32(-2.02)$ & $-12.20(-9.24)$ & $-11.85(-7.22)$ & $-9.82(-7.81)$ & $-10.51(-7.82)$ \\
\hline $\mathbf{3}$ & $-0.30(-2.29)$ & $-13.33(-8.93)$ & $-13.01(-6.64)$ & $-9.99(-2.77)$ & $-10.63(-7.36)$ \\
\hline $\mathbf{4}$ & $-1.06(-1.68)$ & $-12.94(-9.13)$ & $-11.87(-7.44)$ & $-7.50(-3.63)$ & $-9.64(-7.00)$ \\
\hline $\mathbf{5}$ & $-2.38(-1.53)$ & $-12.39(-6.71)$ & $-10.00(-5.17)$ & $-6.54(-1.96)$ & $-11.32(-5.05)$ \\
\hline $\mathbf{6}$ & $-0.77(-0.94)$ & $-11.37(-5.91)$ & $-10.59(-4.95)$ & $-7.53(-1.53)$ & $-9.09(-3.44)$ \\
\hline $\mathbf{7}$ & $-1.57(-1.17)$ & $-13.80(-6.91)$ & $-12.21(-5.74)$ & $-8.22(-3.17)$ & $-11.40(-5.53)$ \\
\hline $\mathbf{8}$ & $-2.66(-2.38)$ & $-16.16(-9.54)$ & $-13.47(-7.16)$ & $-8.97(-11.45)$ & $-14.35(-9.47)$ \\
\hline $\mathbf{9}$ & $-0.35(0.52)$ & $-11.29(-5.87)$ & $-10.92(-6.37)$ & $-8.40(-5.89)$ & $-9.16(-4.89)$ \\
\hline $\mathbf{1 0}$ & $-0.17(0.04)$ & $-11.04(-6.29)$ & $-10.85(-6.31)$ & $-8.68(-4.86)$ & $-9.06(-4.81)$ \\
\hline
\end{tabular}

${ }^{a}$ Since there are internal rotations due to the guest molecule, the zero-point corrections were added to the electronic energies to account for errors caused by these motions. 


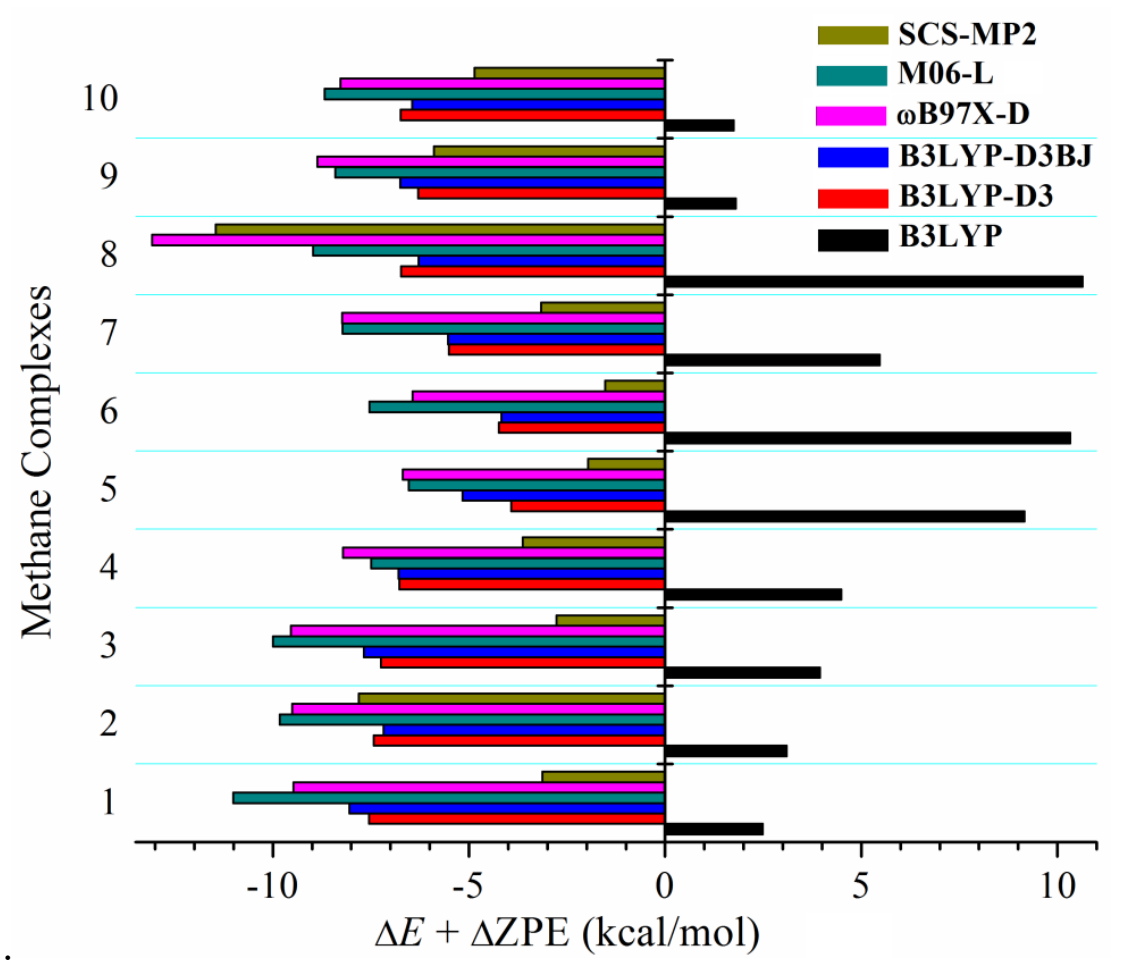

Figure 5. The stabilization energies (calculated using Eq. 3) of the $\mathrm{CH}_{4} @$ cryptophane complexes calculated using different functionals.

Table 3. Comparison of the stabilization energies $\left(\Delta G_{\text {stab}}\right)$ (all in $\mathrm{kcal} / \mathrm{mol}$ ) of the Xe@cryptophane complexes calculated using different functionals.

\begin{tabular}{|c|c|c|c|c|c|}
\hline Xe@ & B3LYP & B3LYP-D3 & B3LYP-D3BJ & $\omega B$ B7X-D & M06-L \\
\hline $\mathbf{1}$ & 12.34 & -3.75 & -4.45 & -5.51 & -6.93 \\
\hline $\mathbf{2}$ & 12.06 & -2.93 & -2.52 & -3.15 & -6.54 \\
\hline $\mathbf{3}$ & 14.54 & -3.67 & -3.87 & -3.50 & -5.10 \\
\hline $\mathbf{4}$ & 14.56 & -1.96 & -2.56 & -3.01 & -3.41 \\
\hline $\mathbf{5}$ & 23.46 & 2.71 & 2.10 & 5.33 & 0.10 \\
\hline $\mathbf{6}$ & 23.46 & 3.84 & 2.66 & 7.18 & 2.22 \\
\hline $\mathbf{7}$ & 16.62 & -0.05 & -1.12 & -1.49 & -2.56 \\
\hline $\mathbf{8}$ & 11.34 & -4.47 & -4.87 & -5.21 & -3.63 \\
\hline $\mathbf{9}$ & 10.11 & -2.28 & -2.75 & -4.88 & -4.51 \\
\hline $\mathbf{1 0}$ & 9.70 & -2.40 & -2.97 & -3.94 & -4.22 \\
\hline
\end{tabular}


Table 4. The cage deformation $\left(E_{\text {deform }}\right)$, interaction $\left(E_{\text {int }}\right)$, binding $\left(\Delta E_{\text {bind }}\right)$, zero-point vibrational $\left(\Delta E_{\mathrm{ZPVE}}\right)$, and stabilization energies $\left(\Delta E_{\text {stab }}\right)$ (all in $\mathrm{kcal} / \mathrm{mol}$ ) of the Xe@cryptophane complexes calculated using M06-L/6-311G(d,p) (without parenthesis) and SCS-MP2/cc-pVDZ (in parenthesis).

\begin{tabular}{|c|c|c|c|c|c|}
\hline $\mathrm{Xe} @$ & $\Delta E_{\text {deform }}$ & $\Delta E_{\text {int }}$ & $\Delta E_{\text {bind }}$ & $\Delta E_{(\mathrm{ZPVE})}{ }^{\mathrm{a}}$ & $\Delta E_{\text {stab }}$ \\
\hline $\mathbf{1}$ & $-0.41(-1.04)$ & $-16.56(-7.90)$ & $-16.97(-8.94)$ & $-15.38(-6.87)$ & $-16.20(-8.17)$ \\
\hline $\mathbf{2}$ & $-0.99(1.02)$ & $-14.90(-10.09)$ & $-15.89(-9.08)$ & $-13.65(-10.66)$ & $-15.63(-8.81)$ \\
\hline $\mathbf{3}$ & $-1.12(-2.22)$ & $-16.66(-9.91)$ & $-17.78(-12.13)$ & $-14.39(-7.34)$ & $-16.62(-10.97)$ \\
\hline $\mathbf{4}$ & $-2.06(-2.53)$ & $-14.06(-13.33)$ & $-16.13(-15.86)$ & $-11.21(-11.29)$ & $-15.34(-15.07)$ \\
\hline $\mathbf{5}$ & $-2.07(-1.45)$ & $-10.23(-9.42)$ & $-12.30(-10.88)$ & $-8.53(-7.80)$ & $-11.94(-11.24)$ \\
\hline $\mathbf{6}$ & $-3.06(-1.25)$ & $-10.41(-8.90)$ & $-13.47(-10.16)$ & $-7.35(-6.87)$ & $-13.46(-10.15)$ \\
\hline $\mathbf{7}$ & $-3.00(-1.17)$ & $-15.08(-11.74)$ & $-18.08(-12.92)$ & $-11.45(-10.65)$ & $-17.44(-12.28)$ \\
\hline $\mathbf{8}$ & $-2.84(1.02)$ & $-16.03(-11.02)$ & $-18.86(-10.00)$ & $-12.40(-12.06)$ & $-18.07(-9.20)$ \\
\hline $\mathbf{9}$ & $-0.73(0.69)$ & $-14.00(-12.48)$ & $-14.73(-11.79)$ & $-12.92(-13.10)$ & $-14.39(-11.44)$ \\
\hline $\mathbf{1 0}$ & $-0.24(2.96)$ & $-13.95(-10.15)$ & $-14.20(-7.19)$ & $-12.71(-12.66)$ & $-13.20(-6.19)$ \\
\hline
\end{tabular}

${ }^{a}$ Since there are internal rotations due to the guest molecule, the zero-point corrections were added to the electronic energies to account for errors caused by these motions.

Table 5. NMR chemical shifts of the Xe@cryptophane complexes calculated using SOZORA/B3LYP/TZ2P. The absolute shielding constant of free $\mathrm{Xe}$ is used as reference. The ${ }^{13} \mathrm{C}$ and ${ }^{1} \mathrm{H}$ chemical shifts refer to the $\mathrm{CH}_{4} @$ cryptophane complexes.

\begin{tabular}{|c|c|c|c|c|}
\hline \multirow{2}{*}{} & \multicolumn{2}{|c|}{ Xe@ cryptophane } & \multicolumn{2}{c|}{$\mathrm{CH}_{4} @$ cryptophane } \\
\cline { 2 - 5 } & $\delta\left({ }^{129} \mathrm{Xe}\right)(\mathrm{gas})$ & $\delta\left({ }^{129} \mathrm{Xe}\right)\left(\mathrm{H}_{2} \mathrm{O}\right)$ & $\delta\left({ }^{13} \mathrm{C}\right)\left(\mathrm{H}_{2} \mathrm{O}\right)$ & $\delta\left({ }^{1} \mathrm{H}\right)\left(\mathrm{H}_{2} \mathrm{O}\right)$ \\
\hline $\mathbf{1}$ & 55.54 & 87.71 & -5.81 & -3.54 \\
\hline $\mathbf{2}$ & 59.43 & 49.31 & -7.47 & -4.37 \\
\hline $\mathbf{3}$ & 75.25 & 64.40 & -4.77 & -4.40 \\
\hline $\mathbf{4}$ & 83.70 & 70.23 & -5.67 & -4.89 \\
\hline $\mathbf{5}$ & 188.56 & 161.99 & -2.58 & -5.18 \\
\hline $\mathbf{6}$ & 177.21 & 148.07 & -2.58 & -5.36 \\
\hline $\mathbf{7}$ & 94.48 & 81.54 & -4.06 & -3.95 \\
\hline $\mathbf{8}$ & 102.80 & 92.45 & -5.67 & -4.11 \\
\hline $\mathbf{9}$ & 103.27 & 125.09 & -4.45 & -3.03 \\
\hline $\mathbf{1 0}$ & 110.87 & 103.13 & -5.53 & -3.38 \\
\hline
\end{tabular}

The ${ }^{129} \mathrm{Xe}$ chemical shifts are scaled using $\delta_{\text {scaled }}=\left(\delta_{\text {calc }}+30.97\right) / 1.198$; which is shown to provide good correlations between the calculated and experimental ${ }^{129} \mathrm{Xe}$ chemical shifts. ${ }^{18}$ 